\title{
O Ensino da Comunicação no Internato e Residência Médica: Relato de Experiência em Serviço de Atenção Primária à Saúde
}

\author{
Bivanco-Lima, Danielle; Moura, Juliana de Carvalho; Kiso, Karina de Moraes; Sizilio, Alexandre; \\ Vannucchi, Ana Maria Cortez; Santos, Verena Castellani Vitos; Carneiro Junior, Nivaldo \\ Faculdade de Ciências Médicas da Santa Casa de Sp — danielle.bivanco@gmail.com
}

Introdução: o ensino de competências de comunicação para alunos de graduação de medicina é recomendada pelas Diretrizes Curriculares Nacionais para o Curso de Graduação em Medicina. nas Diretrizes para o Ensino na Atenção Primária à Saúde na Graduação em Medicina discute-se a necessidade de construir competências para realização da abordagem centrada na pessoa, de encontro com os objetivos da Política Nacional de Humanização, que enfatiza a valorização das dimensões subjetivas e sociais dos sujeitos no cuidado à saúde, com vistas ao seu empoderamento e autonomia. Objetivos: Descrever a incorporação do ensino de competências de comunicação centradas no paciente e as estratégias pedagógicas utilizadas, utilizando os conceitos da Medicina Centrada no Paciente em estágio curricular do internato e da residência em clínica médica de instituição de ensino no município de São Paulo, no contexto da Atenção Primária à Saúde. Métodos: a partir de 2012, a partir de discussão entre participantes da disciplina de internato em Atenção Primária, foram incorporadas quatro horas mensais de treinamento em Medicina Centrada no Paciente (MCP) no estágio mensal dos estudantes do quinto ano da graduação médica. a partir do segundo semestre de 2013, foram incorporadas oito horas mensais de treinamento em competências de comunicação no estágio mensal de Atenção Primária dos residentes de clínica médica (do primeiro e segundo anos). Resultados e discussão: a experiência do ensino das competências de comunicação centradas no paciente junto aos internos inclui a utilização de metodologias ativas de ensino-aprendizagem compostas por: a) atividades de simulação de atendimentos com pacientes previamente estruturados e discussão da experiência; b) uso de ficha de entrevista médica estruturada nos conceitos da MCP na assistência aos usuários do serviço de Atenção Primária; c) discussão de casos individualmente com enfoque na interação entre alunos e pacientes, utilizando a estratégia do preceptor-minuto. Os residentes participam de discussões e do ambulatório de comunicação no qual são avaliados a partir de observação direta das consultas individuais (após o consentimento dos pacientes). Os preceptores utilizam instrumentos estruturados e validados (Calgary-Cambridge e o consenso de Kalamazoo) para a observação e para as discussões problematizando a experiência, com devolutiva em grupo. Todos participantes avaliaram a experiência de forma positiva, tanto pela oportunidade de avaliar um aspecto pouco discutido na graduação e especialização, evidenciando a indissociabilidade da comunicação com os demais aspectos do cuidado integral ao usuário. Conclusões: a incorporação do ensino de competências de comunicação na graduação de medicina e na residência médica é central na humanização do cuidado à saúde e pode ser incorporada a rotina de ensino e dos campos de estágios, através da capacitação dos preceptores e da utilização de metodologias ativas.

Bivanco-Lima, Danielle; Moura, Juliana de Carvalho; Kiso, Karina de Moraes; Sizilio, Alexandre; Vannucchi, Ana Maria Cortez; Santos, Verena Castellani Vitos; Carneiro Junior, Nivaldo. O Ensino da Comunicação no Internato e Residência Médica: Relato de Experiência em Serviço de Atenção Primária À Saúde. In: Anais do Congresso Internacional de Humanidades \& Humanização em Saúde [= Blucher Medical Proceedings, num.2, vol.1]. São Paulo: Editora Blucher, 2014. ISSN 2357-7282

DOI 10.5151/medpro-cihhs-10807 